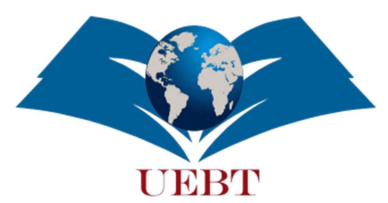

Uluslararası Eğitim Bilim ve Teknoloji Dergisi

\title{
MOBİL ÖĞRENME ARACI OLARAK PODCASTIN TÜRKÇE ÖĞRETIMINDE KULLANILABİLİRLİĞİ ÜZERİNE: KURAMSAL BİR ÇALIŞMA
}

\author{
Akife KURT $^{*}$, Ali GÖÇER ${ }^{* *}$
}

\begin{abstract}
Özet
Teknoloji, dünyada meydana gelen değişikliklerin başrolünü üstlenmiştir. Teknoloji, zaman içinde insanların tutumu, tüketim alışkanlığı, bilgi ve beceri yönetimi üzerinde rol oynadığı gibi kullanılan cihazların şeklini, işlevini değiştirmiştir. Bunun sonucunda cihazlar, küçülerek taşınabilir hâle gelmiş ve işlevi bakımından bilgisayardan farksızlaşmıştır. Web 2.0'ın eğitim ve öğretim ortamlarında yer almaya başlamasıyla akıllı telefon, e-okuyucu, tablet gibi mobil cihazlar hayatın bir parçası olmuş ve kullanım oranı artmış̧ır. Mobil cihazlar, yapılandırmacı yaklaşımın amaçlarıyla örtüşecek özellikler barındırmaktadır. Nitekim yer ve zaman bağımsızlığı sunması, kullanıcıyla etkileşim kurması, kullanıcıyı aktif kılması bunlardan bazılarıdır. Mobil destekli bir öğrenme aracı olan podcast, son zamanların sıklıkla kullanılan gözde Web 2.0 araçlarından biridir. Podcastler; ses, video veya Web ile desteklenebilen, yayınlanabilen ve paylaşılabilen bir teknolojidir. İçerik üretimine ve yayıncılığına imkân sağlaması, farklı platformlarda paylaşılabilir olması, kolay kullanımı sayesinde podcastlerin temel dil becerilerinin gelişimini destekleyeceği düşünülmüştür. Literatür incelemesi sonucu podcastlerin hem eğitim hem de dil eğitimi çalışmalarına konu olduğu tespit edilmiştir. Dil eğitimi kapsamında yapılan sınırlı sayıdaki çalışmaları, yabancı dil olarak Türkçe öğretimi oluşturmaktadır. Eğitimde podcast kullanımını içeren çalışmaların sonuçları; podcastin formal ve informal öğrenmeyi desteklediğini, çalışma disiplini kazandırdığını, bilişsel ve duyuşsal gelişime katkı sağladığını göstermiştir. Dil eğitimi temelli çalışmaların sonuçları ise metin tabanlı Web 2.0 aracı olan podcastin temel dil becerilerini gelişiminde önemli görev üstlendiğini ortaya çıkarmıştır. Çalışmada; "Mobil Öğrenme ve Zaman-Mekân Bağımsızlı̆̆ı", "Mobil Ekosisteminin Bir Parçası: Podcast", "Eğitimde Podcast Kullanımı" ve "Türkçe Öğretiminde Podcastin Kullanımı ve Örnek Uygulamalar" başlıklarına yer verilmiş̧tir. Bu başlıklar altında; literatürden hareketle mobil öğrenme ve podcastin kapsamı, podcastin faydaları ve sınırlılıkları ele alınmış, eğitimde ve Türkçe öğretiminde podcastin işlevselliğine ilişkin kuramsal bir çerçeve çizilmiş, Türkçe dersinde temel dil becerilerinin öğretiminde podcastin kullanılabileceği örnek ders planları sunulmuştur.
\end{abstract}

Anahtar Kelimeler: Mobil öğrenme, podcast, Türkçe öğretimi, temel dil becerileri.

\footnotetext{
* Doktora Öğrencisi, Erciyes Üniversitesi Eğitim Bilimleri Enstitüsü, akifekurt93@gmail.com ORCID: 0000-0003-28758406

** Prof. Dr., Erciyes Üniversitesi Eğitim Fakültesi Türkçe Eğitimi Bölümü, gocer@erciyes.edu.tr ORCID: 0000-0002-68802611
} 


\title{
A THEORETICAL STUDY ON THE USABILITY OF PODCASTS AS A MOBILE LEARNING TOOL IN TURKISH LANGUAGE TEACHING
}

\begin{abstract}
Technology has taken the lead in the changes in the world. Technology has changed the shape and function of the devices used, as well as playing a role on people's attitudes, consumption habits, knowledge and skill management over time. As a result, the devices have become smaller, more portable, and indistinguishable from computers in terms of functionality. With the introduction of Web 2.0 in education and training environments, mobile devices such as smartphones, e-readers and tablets have become a part of life, and their usage rate has increased accordingly. Mobile devices contain features that can overlap with the objectives of the constructivist approach. Some of these can be listed as providing independence of space and time, interacting with the user, activating the user. Podcasts, a mobile-assisted learning tool, is one of the popular Web 2.0 tools of recent times. Podcasts offer a technology that can be supported, broadcast and shared with audio, video or the Web. It is believed that podcasts will support the development of basic language skills thanks to the possibility of content production and broadcasting, shareability on different platforms and easy use. As a result of the literature review, it has been determined that podcasts are the subject of both education and language education studies. The limited number of studies carried out within the scope of language education consists of teaching Turkish as a foreign language. Results of studies involving the use of podcasts in education; it has been shown that podcast supports formal and informal learning, gains working discipline and contributes to cognitive and affective development. The results of language education-based studies revealed that podcast, which is a text-based Web 2.0 tool, plays an important role in the development of basic language skills. The present study covers the titles of "Mobile Learning and Time-Space Independence", "Podcast as a Part of the Mobile Ecosystem", "Use of Podcasts in Education" and "Use of Podcasts in Turkish Language Teaching and Sample Practices". Under these headings; based on the literature, mobile learning and the scope of podcast, the benefits and limitations of podcast are discussed, a theoretical framework is drawn regarding the functionality of podcast in education and Turkish teaching, sample lesson plans where podcast can be used in teaching basic language skills in Turkish lesson are presented.
\end{abstract}

Keywords: Mobile learning, podcast, Turkish teaching, basic language skills.

\section{GIRIŞ̧}

Teknolojinin insan hayatına dâhil olması; insanların davranışlarında, beklentilerinde, beslenmelerinde, tüketimlerinde, bilgi ve becerilerinde birtakım değişiklikler meydana getirmiştir. Bireylerin değişimi, iletişim ve sosyal hayatlarında da etkili olmuştur. Bilgiye ulaşma sınırlarının aşılması, günlük yaşamda yeri olan mobil cihazların küçülmesine, taşınabilmesine ve mobil cihazlara her kesimden insanın erişebilmesine imkân sağlamıştır. Bu sayede öğrenmenin mobil biçimiyle tanışılmıştır. Mühendislik, tarih, tıp, turizm, spor gibi alanlarda etkililiğini sürdüren mobil öğrenme, dil öğretiminde de kullanılmıştır. Özellikle ses, görüntü ve Web bağlantılarıyla zenginleştirilmiş çoklu ortamların eğitimde kullanımı, dijital yerli denilen hedef kitlenin dikkatini çekmiş, artan ihtiyaçlarına cevap vermiştir.

Mobil cihazların yaygınlaşması sonucunda Web 2.0, yaşamı dört bir yandan kuşatmıştır. “Web 2.0’ın sahip olduğu en önemli özellikler, zengin kullanıcı katılımı, dinamik içerik, metadata ve toplu zekâ olarak sayılabilir" (Chen, Hwang, Wang, 2012; akt. Karaoğlan Yılmaz, 2014: 17). Bu özellikler; çoklu ortam, kullanıcılar arası etkileşim, arayüz tasarımı ve özelleştirme gibi olanaklar sunar. Böylece kullanıcılar ve kullanıcıların bağlantıda olduğu kişilerin bilgiye erişimi kolaylaşır. İnsanlar, Web 2.0 araçları vasıtasıyla tüketici 
rolünün yanında üretici kimliğine bürünmüş ve öğrenme farkındalığg kazanmıştır. Nitekim “Web 2.0'ın kullanıcılarına sağladıklarını, McLoughlin ve Lee (2007) bağlantılılık ve toplumsal uyum, iş birlikli bilgi keşfi ve paylaşım, içerik oluşturma, bilgi toplama ve içeriği değiştirme (yeniden birleştirme, yeniden hazırlama)" (Altıntaş, 2012: 6) sözleriyle sıralaması bunun bir göstergesidir.

Yenileşme esnasında çağa uyum sağlamak, araştırmak, öğrenmek, eleştirmek, analiz etmek zihinsel ve dilsel gelişim ile doğru orantılı ilerlemektedir. İnsanın değişime adapte olurken dil bilincini yitirmemesi ve onu güçlendirmesi önemlidir. Dolayısıyla ana dilin temellerini sağlamlaştırmak için Web 2.0 teknolojisinin güçlü yönlerinden yararlanılmalıdır. "Metin, görsel, video gibi farklı formatlardaki içerikleri herhangi bir kodlama becerisine sahip olmaksızın, düzenlemeye ve yayınlamaya imkân veren Web 2.0 araçlarının" (Yeşiltaş, 2020: 220) bir bölümünü bloglar, podcastler, wikiler, sosyal ağlar temsil etmektedir. Bir Web 2.0 aracı podcast, kullanıcının çeşitli ekipmanlarla kaydettiği ses ya da video dosyasını Web sitesine yüklemesi ile meydana gelmektedir. Mobil cihazlar sayesinde yaşam alanında daha çok yer edinen podcast, dinleyici/izleyiciler tarafından indirilebilir ve paylaşılabilir özelliktedir.

Podcastin farklı ortamlara iletimi, etkileşimselliği, taşınabilirliği, ekonomikliği ve sosyal medyadaki popülerliği onu son zamanların rağbet görülen teknolojisi hâline getirmiştir. Sahip olduğu özellikler dikkate alınarak podcastin eğitim ile ilişkisi, hangi alanlarda kullanılabileceği, faydaları ve sınırlılıkları üzerine düşünülmüş, literatür taraması yapılmıştır. Literatür taraması sonucu podcastin işlevi, kullanım amacı, önemi, eğitim üzerindeki etkililiği, dil öğretimindeki rolü üzerine yurt içi ve yurt dışında çalışmaların yapıldı̆̆ fark edilmiştir.

Podcastin özellikle 2000'li yıllardan sonra arttığı ve yabancı dil çalışmalarında kullanıldığı tespit edilmiştir. Bu çalışmaların içinde Yabancılara Türkçe Öğretimi ile ilgili Berk'in (2019) "Yabancı Dil Olarak Türkçe Öğretiminde Elektronik Dinletilerin Dinlediğini Anlama Başarısı ve Dinleme Kaygısına Etkisi” adlı bir doktora tezine; Yılmaz ve Babacan'ın (2015) "Yabancı Dil Olarak Türkçe Öğretiminde Podcast Kullanımı" ve Coşkun ve Demirkan'ın (2016) "Türkçenin Yabancı Dil Olarak Öğretiminde Dinleme Becerisini Geliştirmede Web Radyo ve Podcast Uygulamaları" adlı makalelerine rastlanmıştır. Literatürdeki bilgiler 1şığında, yabancı dil olarak Türkçenin öğretiminde podcast kullanımına ilişkin sınırlı sayıda çalışmanın bulunmasına karşın ana dili olarak Türkçenin öğretiminde podcast kullanımına ilişkin çalışmaya rastlanmamış ve bu durumun eksiklik teşkil ettiği sonucuna varılmıştır. Dolayısıyla mobil destekli öğrenme aracı olan podcastin ana dili olarak Türkçenin öğretiminde temel dil becerilerinin desteklemesi açısından tamamlayıcı bir rol oynayabileceği kanaati oluşmuştur.

\section{1. Çalışmanın Amacı ve Önemi}

$\mathrm{Bu}$ çalışma, mobil destekli öğrenme aracı olan podcastlerin Türkçe öğretiminde kullanılabilirliğini göstermek amacıyla yapılandırılmıştır. Çalışmanın amacı kapsamında "Mobil Öğrenme ve Zaman-Mekân Bağımsızlığı", "Mobil Ekosisteminin Bir Parçası: Podcast", "Eğitimde Podcast Kullanımı" ve "Türkçe Öğretiminde Podcastin Kullanımı ve 
Örnek Uygulamalar" başlıkları altında literatür taraması sonucu elde edilen kuramsal bilgilere yer verilmiş ve örnek uygulamalar gösterilmiştir. Çalışmanın sonunda, mobil öğrenme aracı podcastin Türkçe öğretiminde kullanımına ilişkin tavsiyelerde bulunulmuştur. Otantik bir eğitim aracı olan podcastlerin temel dil becerilerinin gelişimine katkı sağlayabileceği düşünülmüştür. Bu anlayış, çalışmanın önemini de ifade etmektedir.

\section{MOBILL ÖĞRENME VE ZAMAN-MEKÂN BAĞIMSIZLIĞI}

"Mobil öğrenme, mobil bilişim ile e-öğrenme alanlarının birlikte değerlendirilmesi sonucu ortaya çıkan ve belirli bir yere bağlı olmadan e-öğrenme içeriğine erişebilme, dinamik olarak üretilen hizmetlerden yararlanma ve başkalarıyla iletişimde bulunmayı sağlayan öğrenme biçimidir" (Tarımer ve Okumuş, 2010). Mobil öğrenme, mobil cihazlardan yoluyla gerçekleştirilen, zaman ve mekân bağımsızlığı tanıyan yeni nesil öğrenme biçimi olarak tanımlanabilir.

Mobil teknolojinin sunduğu iletim ortamı kullanıcıların ihtiyaç ve ilgilerine göre şekillenmektedir. Mobil cihazların taşınabilirliği, kullanım kolaylığı, erişim imkânı ve "özelliklerinin gelişip bilgisayara yakınlaşmaları sebebiyle mobil öğrenme daha da bir önem kazanmıştır" (Çakır, 2012). Jacob ve arkadaşlarının (2008) çalışması, öğrencilerin mobil öğrenmeye yatkın olduklarını göstermiştir. Çünkü öğrenenler; cep bilgisayarı, akıllı telefon, tablet ve e-okuyucu gibi mobil cihazlar ve kablosuz ağlar sayesinde eğitimi destekleyen materyallere ulaşabilir, kendi öğrenme ortamını kolaylıkla tasarlayabilirler. İlkokuldan üniversite eğitimine kadar eğitimin her kademesinde hem bireysel hem iş birlikli öğrenme şansı tanıyan mobil cihazlar; not alma, not gönderimi, ses kaydı yapma, oyunlaştırma, alıştırma/etkinlik oluşturma, geri bildirim alma, geri bildirimde bulunma, ölçme ve değerlendirme gibi özellikleriyle mühendislik, tıp, reklamcılık, müzik ve eğitim gibi farklı alanlarda hizmete sunulması formal ve informal bilgiye erişimi, bilginin paylaşımını kolaylaştırmıştır. "Ücretsiz veya fiyatı uygun sayısız mobil dil öğrenimi uygulamalarının hızla yayılmasıyla, dil öğrenimi de mobil öğrenme alanındaki gelişmelerde ön plana çıkmıştır" (Öz, 2014: 142).

\subsection{Mobil Ekosisteminin Bir Parçası: Podcast}

Mobil destekli öğrenme araçlarından birini de podcast oluşturmaktadır. Podcast; ses, görüntü ve Web bağlantısı ile içeriği desteklenen bir yayıncılık örneğidir. "Podcast ismi ilk olarak yazar Ben Hammersley'in The Guardian'da 12 Şubat 2004'te yayınladığı makalesinde kullanılmıştır" (Ayvaz Reis ve Kartal, 2009: 26). Podcast, "iPod ve broadcasting kelimelerinden türetilmiş olup Mp3 formatında ses ve video dosyalarının mobil ve kişisel cihazlardan RSS'ler ile takibi sağlanan teknolojidir" (Işık, Özkaraca ve Güler, 2011: 864). Tanımlardan hareketle "dijital içerik, yayınlama ve paylaşma"nın podcast yayıncılığının temelini oluşturduğu söylenebilir. 


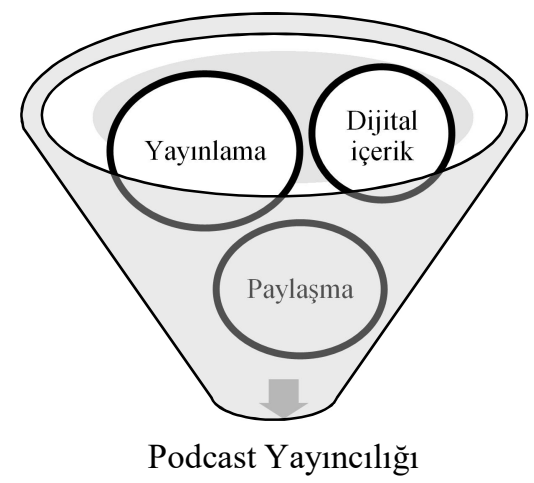

Şekil 1. Podcast yayıncılı̆̆ının temel unsurları

Alan yazında podcast terimi; “cep yayını” (Coşkun ve Demirkan, 2016), "elektronik dinleti, e-dinleti" (Berk, 2019) gibi farklı şekilde isimlendirilmiştir. Bu doğrultuda "çeşitli medya dosyalarını dikkate alarak yapılan bir sınıflandırma ile podcast teknolojisinin 3 türü olduğu ifade edilmektedir" (Traxler, 2008: 47; akt. İspir, 2013: 35):

- Sadece ses içeren "audio (ses) podcast"

- Ses ve görüntü içeren "video (görüntü) podcast"

- Ses podcastlerinin geliştirilmiş ve etkileşimli boyutunu içeren, ses görüntü bilgisine ek olarak Web bağlantıları, bölüm işaretçileri gibi ek bilgileri içeren "geliştirilmiş (enhanced) podcast"

\section{Ses İçerikli Podcast}

Ses, medya türleri içinde ilk kullanılan içeriktir. Podcastte de ilk ve en çok kullanılan tür olarak bilinmektedir. Ses içerikli podcastler, video temelli podcastlere (vodcast) kıyasla oluşturulması basittir. "Ses podcasti oluşturmada bir mikrofon, bir kayıt cihazı ve kurgu yazılımının olması yeterlidir. Ses podcasti oluşturmak için gerekli olan ses bilgisi mikrofon aracılığıyla dijital ses ortamına aktarılacaktır" (İspir, 2013: 35).

\section{Video İçerikli Podcast}

Video içerikli podcastler, sahip olduğu ses ve görüntü hizmetiyle çoklu medya ortamı yaratımına imkân tanıdığı için zengin bir içerik sunar. Vodcast adıyla bilinen bu medya örneğinin oluşturulması kolay olmamakla birlikte maliyetlidir. "Bir vodcast oluşturmak için dijital video kamera ve kurgu programına, dosya formatının belirlenmesi ve hızlı internet erişimine gereksinim vardır” (Salmon, 2008: 48; akt. İspir, 2013: 37).

\section{Geliştirilmiş Podcast}

Podcast yayıncılığının bir çeşidi olan geliştirilmiş podcast, Web bağlantıları sayesinde etkileşimli bir ortam sunmaktadır. "Dijital mobil oynatıcıların sahip oldukları dijital ekran vasıtasıyla podcast kullanıcı uygulamalarına ilişkin görsellerle internet bağlantısıyla erişilebilmektedir. Podcast teknolojisi geliştirilmiş podcast uygulaması ile hem işitsel hem görsel hem de etkileşimli bir teknolojiye dönüşmüştür" (İspir, 2013: 38). 
Türkiye'de podcast kullanımının dünyayla paralel olarak radyo yayınlarının dağıtımıyla ilerlediğini dile getiren Ayvaz Reis ve Kartal (2009: 27-30), M. Serdar Kuzuloğlu'nun hazırladığı ve NTV Radyo'da yayınlanan Sanal Âlem adlı programın podcastinin 16 Mart 2005'te yayınlanarak Türkiye'nin ilk podcasti olduğunu, dünya üzerindeki dönüm noktasının ise 2005 yılının Haziran ayında Apple firmasının iTunes isimli müzik programına podcast desteğinin eklenmesi ve dizin yaratmasıyla meydana geldiğini belirtmiştir. Bugün Türkiye'de podcastten yararlanıldığını gösteren örnekler görmek mümkündür. Bunlardan biri Millî Eğitim Bakanlığının çalışmaları neticesinde oluşturulan TRT EBA'nın “Bizden Veli Kuşağı” adlı podcast yayını, diğeri EBA üzerinde İngilizce öğretimi kategorisinde yer alan podcastlerdir.

Podcast; sağlık, teknoloji, spor, politika, eğitim, dil, kültür ve sanat gibi alanlara ilişkin konu çeşitliliği sunmaktadır. Bu çeşitliliği sayesinde kullanıcı, ilgi ve ihtiyacına uygun kanalı/programı seçebilir ve takip edebilir. "Günümüzde içerik yayınlama araçlarının kullanıcı dostu uygulamalar hâline gelmesi kullanıcıların bu konuda teknik bilgi sahibi olma gerekliliğini azaltmıştır" (Carliner ve Shank, 2008; akt. Ayvaz Reis ve Kartal, 2009: 26). Bunun sonucunda kullanıcıların kendi podcastini oluşturması ve yayınlaması da kolaylaştırmıştır. Podcastlere; Anchor, Spotify, YouTube, Castbox, Talkshoe, Breaker, Himalaya, RadioPublic, Overcast, Google Podcast gibi uygulamalarla ücretli ya da ücretsiz olarak erişilebilir ve yayın yapılabilir. Spotify adlı uygulamanın içinde bulunan sesli podcast kategorileri Görsel 1'de, uygulamanın eğitim kategorisine örnek Görsel 2'de, hikâye kategorisine örnek Görsel 3'te sunulmuştur.

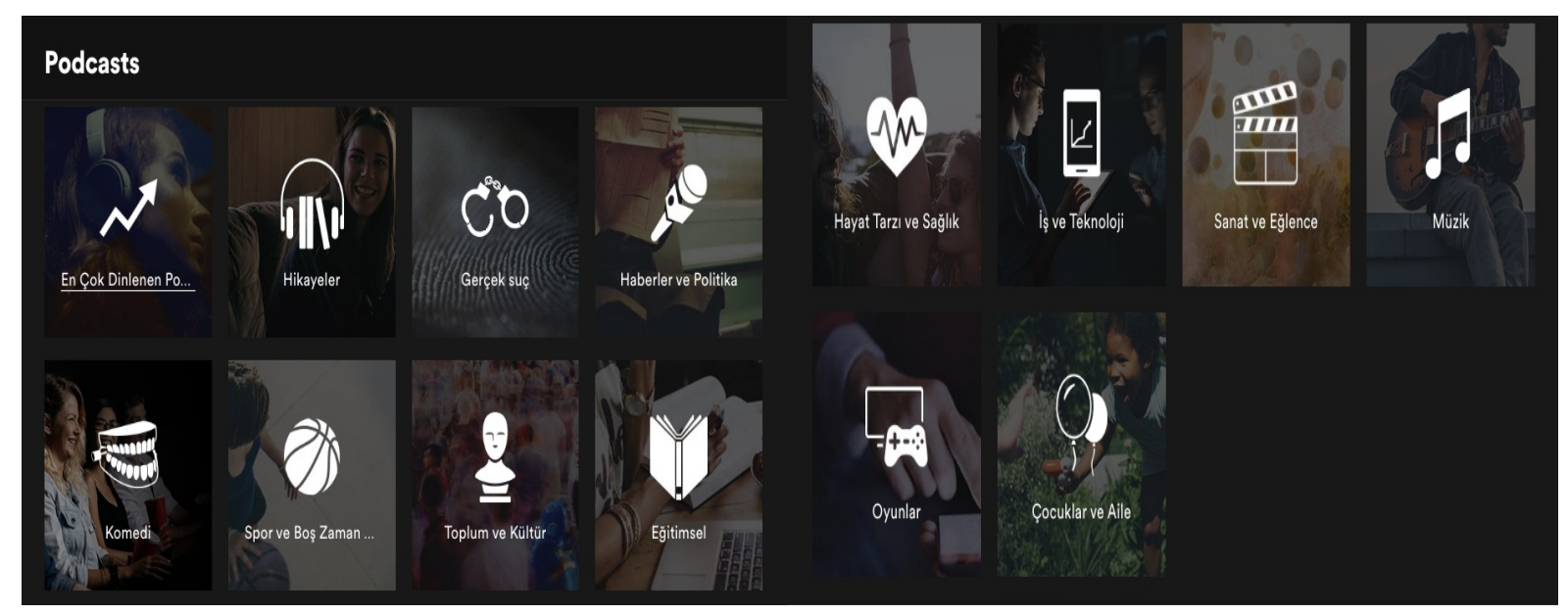

Görsel 1. Spotify uygulamasında yer alan podcast kategorileri 


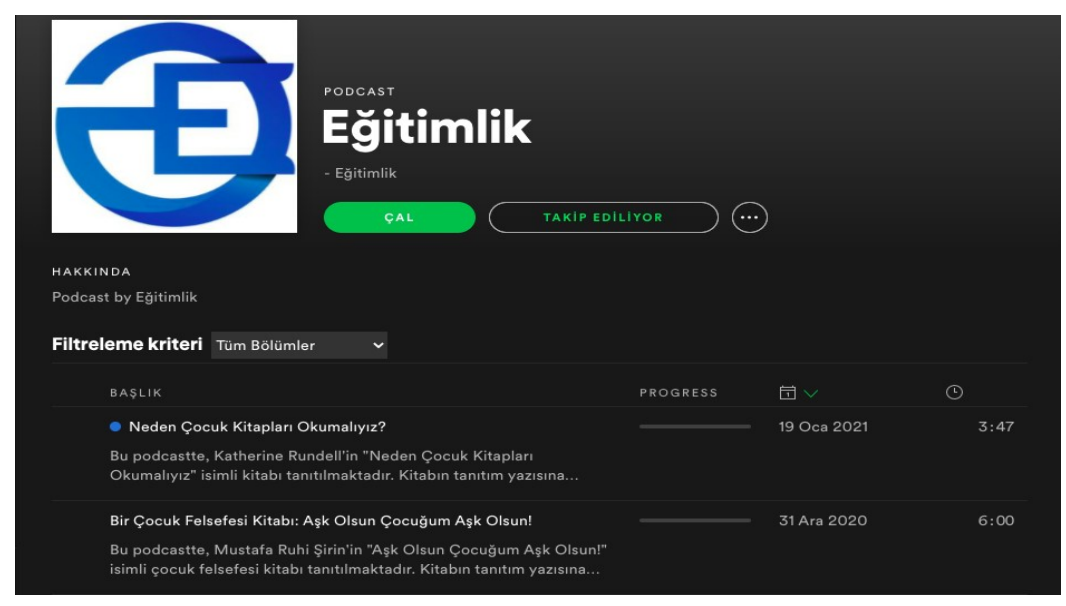

Görsel 2. Spotify uygulamasının eğitimsel kategorisine ait "Eğitimlik" isimli podcast kanalı

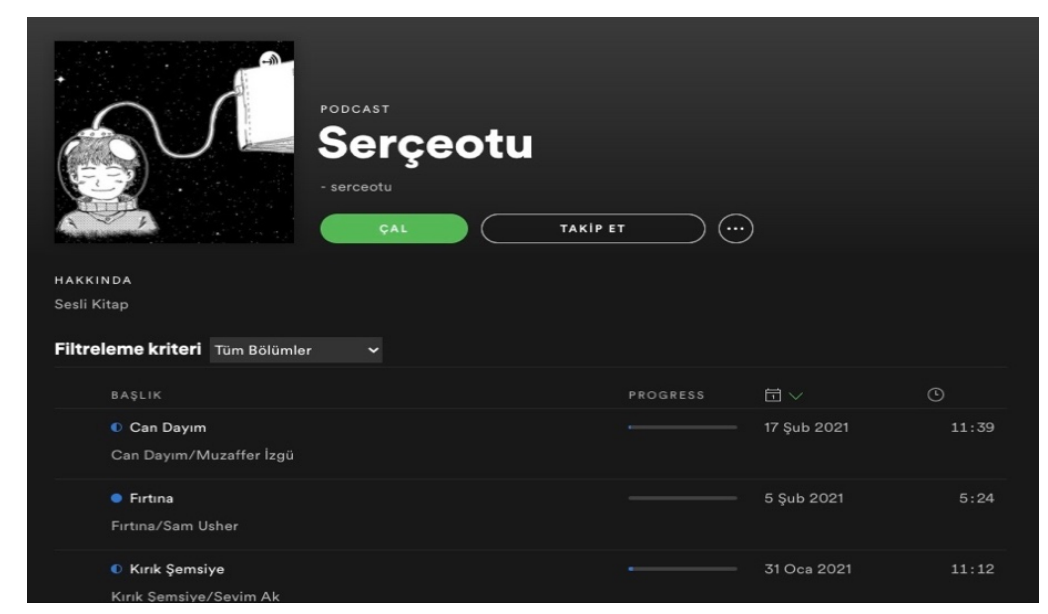

Görsel 3. Spotify uygulamasının hikâye kategorisine ait "Serçeotu" isimli podcast kanalı

\section{Podcast Kullanımının Yararları}

Podcast; taşınabilmesi, mobil cihaz ve bilgisayarda kullanılabilmesi, içerik sunumu ve paylaşımına olanak sağlaması, zaman ve mekân bağımsızlığı, "kullanıcı potansiyelinin fazla olması, farklı öğrenme stillerine hitap etmesi, erişim ve hazırlanmasının ucuz olması" (Cebeci ve Tekdal, 2006: 49) sayesinde popüler bir Web 2.0 aracı olmuştur. Podcastin üstünlüklerini şu ifadelerle özetlemek mümkündür:

- Podcast, zamandan ve mekândan bağımsız olması nedeniyle bireye, günün istediği saatinde ve herhangi bir yerde eğlenme ve öğrenme imkânı sağlar.

- Podcast, internet erişimi olan bireyler için kullanımı kolay ve ekonomiktir.

- Basit bir podcast oluşturmak için ekipmana ihtiyaç yoktur. Mobil cihazı olan her birey, podcast yayını yapabilir.

- Kullanıcilar, podcasti indirebilir, kaydedebilir, tekrar dinleyebilir/izleyebilir veya geri-ileri sarabilir.

- Poscast, doğru kullanıldığında etkili bir eğitim aracı olabilir.

- Podcast, formal ve informal öğrenmeye hizmet eder. 
- Podcast, öğrenciye farklı bir öğrenme ortamı yaratır. Böylece öğrenme, okul dışında da sürdüğü için bireyin sıradışı tecrübeler kazanmasına kapı aralar.

- Podcast, bireyselleştirilmiş öğrenmeye imkân sağlar. Birey, podcast aracılığıyla neyi, nasıl öğrendiğine dair farkındalık kazanır.

- Birey, istediği kanala abone olarak istediği konuda dinleme/izleme yapma şansı bulabilir.

- Podcast dinleyen/izleyen kişi; içeriği beğenme, yorum yapma, paylaşma imkânı sayesinde süreç boyu aktif olur.

Podcast konulu çalışmaların bir kısmı podcastin avantajlı yanını desteklemektedir. $\mathrm{Bu}$ çalışmalar; podcastin öğrenme tutumunu olumlu yönde etkilediğine (Ormond, 2008; Güler, 2014; Şengül, 2014), öğrenme doyumunu artırdığına (Vogt vd., 2010), öz yeterliği geliştirdiğine (Çelik, 2014), dil öğrenimi üzerinde etkili olduğuna (İnce, 2015; Koçak, 2017), eğitimsel araç olarak kullanılabilirliğine (Koçak, 2017) işaret etmektedir.

\section{Podcast Kullanımının Sınırlılıkları}

Web 2.0 araçlarının avantajları olduğu kadar dezavantajları da bulunmaktadır. Ayvaz Reis, Kartal, Çelik ve Özcan (2009: 28), podcastin sınırlılıklarından şu ifadelerle söz etmiştir:

- Bant genişliği ve sistem kaynaklarının sınırlılığg

- Format uygunluğu sorunu

- Ortak platform eksikliği

- Küçük ekran boyutu

- Kablosuz bağlantı sorunu

Akademik çalışmaların bir kısmında podcast kullanımının az olduğu, podcast hakkında bilgi sahibi olunmadığı, eğitim aracı olarak her zaman yararlanılamayacağını gösteren sonuçlarla karşılaşılmıştır. Atal ve Usluel (2011), ilköğretim öğrencilerinin okul içi ve dışındaki teknoloji tüketimine ilişkin çalışmasında ilköğretim öğrencilerinin en fazla Facebook, YouTube gibi Web uygulamalarını; en az blog ve wikiyi kullandıklarını tespit ederken podcastten hiç söz etmediklerini; Altıntaş (2012), çalışmasında öğrencilerin en fazla Facebook ve arama motorlarını; en az ise Twitter, blog ve wiki yazma, okuma ve podcast oluşturma uygulamalarını kullandıklarını; Atal (2010) ise öğrencilerin günlük hayattaki teknoloji kullanımının beklentilerini şekillendirdiğinden söz ederek öğrencilerin derslerde en fazla MSN ve Facebook; en az ise podcast ve wikiyi kullanmayı beklediklerini tespit etmiştir. Mckinney, Dyck ve Luber (2009) yaptıkları araştırmada podcastin kullanışlılığına ilişkin öğrencilerden veri toplamıştır. Araştırmanın sonucunda öğrencilerin podcasti kullanışlı bulmadığı ortaya çıkmıştır.

\subsubsection{Eğitimde podcast kullanımı}

Yapılandırmacı paradigmanın merkeze alınması ve teknolojinin ivme kazanması, eğitimde dönüşümün ve değişimin yolunu açmıştır. Özellikle Web 2.0 araçlarının sağliktan ekonomiye, sanattan eğitime kadar birçok alana yayılması, kullanıcıların dijital ortamla kurduğu etkileşimi artırmıştır. Böylece insanların "içeriğe yorum yapmasına, katkı 
getirmesine" (Karaoğlan Yılmaz, 2014: 16), paylaşmasına ve hayat boyu öğrenmesine yardımcı olmuştur. Yeni nesil gençlerin teknolojiye olan yakınlık ve yatkınlıkları, eğitim sistemini güncel tutmayı ve teknolojinin getirdiği imkânlardan yararlanmayı gerekli kılar (Gülseçen, Gürsul, Bayrakdar, Çilengir, Canım, 2010: 791). Göçer ve Moğul'un (2011: 808) da belirttiği üzere "geleneksel yöntemler bir kenara bırakılarak çağdaş yaklaşım, yöntem ve tekniklerin kullanımına dayalı, uygun materyallerle zenginleştirilmiş" eğitim ortamları oluşturulmalıdır.

Eğitimi yakından ilgilendiren Web 2.0 teknolojisinin tanıştırdığı araçlardan biri de podcast olmuştur. "Rosell-Aguilar'a (2007) göre, podcast teknolojisi; bir bireyin aktif keşif, gözlem, işleme ve yorumlama yoluyla inşa ettiği öğrenmeye yönelik yapılandırmacı yaklaşımlarla güçlü bir şekilde bağlantılıdır” (Hasan ve Hoon, 2013: 129). Başta yalnızca bilgi paylaşım ve eğlence amacıyla kullanılan e-dinletiler, sonraları hazırlığındaki kolaylık fark edilmiş ve taşınabilir medya oynatıcılarının yaygınlaşmasının sonucu olarak eğitimöğretim ortamlarına taşınmıştır (Berk, 2019: 49). "Bazı pedagojik avantajları olması nedeniyle" (Cebeci ve Tekdal, 2006: 49) alternatif bir eğitim aracı olarak da değerlendirilen "podcastin, mobil cihazlarla da kullanılabilmesi, onun mobil öğrenmenin başka bir çeşidi olduğunu göstermektedir" (Kaplan-Leiserson, 2005; akt. Usluel ve Mazman, 2009: 92). Eğitimde podcast kullanımı üzerine yapılan çalışmalardan biri Lane'ye (2006) aittir. Lane (2006), podcast ile sunulan derslerin üniversite öğrencileri ve öğretmenler açısından nasıl değerlendirildiğini araştırmıştır. Anket verileri, podcastin öğrenmeye katkıda bulunduğunu ve bireysel öğrenmeyi destekleyerek öğrenen açısından yararlı olduğunu göstermiştir. Kay (2012), literatürde podcast kapsamında yapılan çalışmaları derlemiş ve podcastin öğrenmeyi desteklediği, çalışma disiplini sağladığı, öğrenme sürecinde bilişsel ve duyuşsal bakımdan destekleyici bulmuştur.

Eğitim amaçlı oluşturulacak podcastlerde dikkat edilmesi gereken noktalar şu ifadelerle dile getirilebilir:

- Podcastler, öğrenci yaş ve seviyesine uygun olmalıdır.

- Podcastlerin içeriği, öğrenci beklenti ve ihtiyaçlarını karşılamalıdır.

- Ses temelli podcastlerin ses kalitesi, video temelli podcastlerin görüntü ve ses kalitesi anlaşılır olmalı; geliştirilmiş podcastlerin içeriğindeki Web adresleri hata barındırmamalı ve etkileşimli olmalıdır.

- Podcastler, doğru şekilde kategorize edilerek kullanıcıya kolaylık sağlamalıdır.

- Podcastlerin sunulduğu Web sayfası tasarımına dikkat edilmeli ve hedef kitlenin ilgisini çekmelidir.

- Podcastlerin uzunluğu iyi ayarlanmalı ve dikkat dağıtacak ögelerden (nesnelerden çıkan hışırtı ve tıkırtılar, patlayan sesler, yutkunma sesleri) arındırılmalıdır.

- Podcast, içeriği bakımından dinleyen/izleyen için merak uyandırmalı, güdülemelidir.

Edirisingha, Rizzi ve Rothwell (2007: 100), öğrencilerin öğrenmesini destekleyen podcastlerin üç temel özelliğinden söz eder: 
- Öğrenen seçimi ve esneklik

- Tartışmalar yoluyla akranlarının örtük bilgilerine erişim

- İnformal öğrenme yolu

Ders içeriklerini paylaşmak, kazanımlara uygun içerik hazırlamak, öğrencilerin hazırladığı proje ve performans görevlerini sergilemek, ders kitaplarını desteklemek, dersi monotonluktan kurtarmak, öğretmen-öğrenci, öğrenci-öğrenci arasında etkileşimde bulunmak üzere yüz yüze, harmanlanmış veya uzaktan eğitim sürecinde podcastten yararlanılabilir.

\subsubsection{Türkçe öğretiminde podcastin kullanımı ve örnek uygulamalar}

Türkçe dersi, temeli metne dayanan bir bilim ve sanat dersidir. Kullanılan eğitim materyallerinin Türkçenin yapı ve özelliklerini destekleyici ve zenginleştirici nitelikte olması beklenmektedir. Dil öğretiminde teknoloji kullanımının gelişim sürecine bakıldığında bu süreci etkileyen iki temel unsurdan birisi sosyal bilimler alanında ortaya çıkan kuramların dil öğrenim alanında yaptığı etkiler, diğeri ise bilişim teknolojilerinde yaşanan gelişmelerdir (Boz ve Çoban, 2015: 1). Teknolojinin hızlı ilerleyişiyle "sesin rönesans yaşaması" (Scholsser ve Burmeister, 2006; akt. Edirisingha, Rizzi, Rothwell, 2007: 89) ve "mobil cihazlarnn yaygınlaşması dil öğrenim çalışmalarına yardımcı olmaktadır" (Yılmaz ve Babacan, 2015: 1157). Özellikle "metin tabanlı çalışma materyalleri için bir tercih olarak" (Carvalho vd., 2008; Kazlauskas ve Robinson, 2011; akt. Altıntaş, 2012: 13) özgün bir Web 2.0 aracı olan podcast kullanılmaktadır.

Coşkun ve Demirkan (2016: 38), "Podcast Uygulamalarının Türkçe Öğretimindeki Yeri ve Önemi Nedir?" alt başlı̆ıına yer verdiği çalışmasında, otantik materyal olarak gördügü podcast yayınlarının dil öğrenimine olan katkılarını şu sözlerle aktarmıştır:

- Öğrenilen dil gerçek hayattan kesitler sunar. Buna bağlı olarak dili öğrenen adaylar, sözlü anlatım becerilerini güçlendirir ve dili konuşurken kendilerine has bir tavir benimserler.

- Yazılı ders kitabında yer almayan fakat öğrenciler için son derece önemli yardımcı materyal niteliği taşırlar.

- Sosyo-kültürel unsurların da aktarıldığı üslubu yansıtarak dilin farklı kullanımlarına aşina olmalarını sağlar.

- Dili öğrenen kişiler artık başkalarının dinleme hızına ayak uydurmak zorunda değildirler. Kendi seviyelerine göre dinleme hızlarına karar verebilir, dinleme etkinliklerini kendileri yönetirler (Cuq ve Gruva, 2003; akt. Sancle, 2012: 59).

Podcastler ses, ses ve görüntü (video) ve Web bağlantılarıyla çeşitlilik gösteren bir yayıncılık örneğidir. Bünyesindeki çeşitlilik; etkili dinleme ve dinlediğini anlamayı, telaffuz ve diksiyon eğitimini, kelime dağarcığını artırmayı, metinler arası bağlantı kurmayı, dikte çalışmaları yapmayı, doğru gramer kullanımını, görsel düşünmeyi destekleyebilir. Podcastler, özgün içerik yaratımı sayesinde öğretici ve öğrenci tarafından hazırlanabildiği gibi ders kitaplarına alternatif bir eğitim aracı olarak kullanılabilir. Rosell-Aguilar'ın (2007: 476) çalışmasından esinlenilerek aşağıda dil öğretiminde podcastin kullanım seçeneklerine işaret eden bir sınıflama yapılmış ve Şekil 2'de sunulmuştur. 


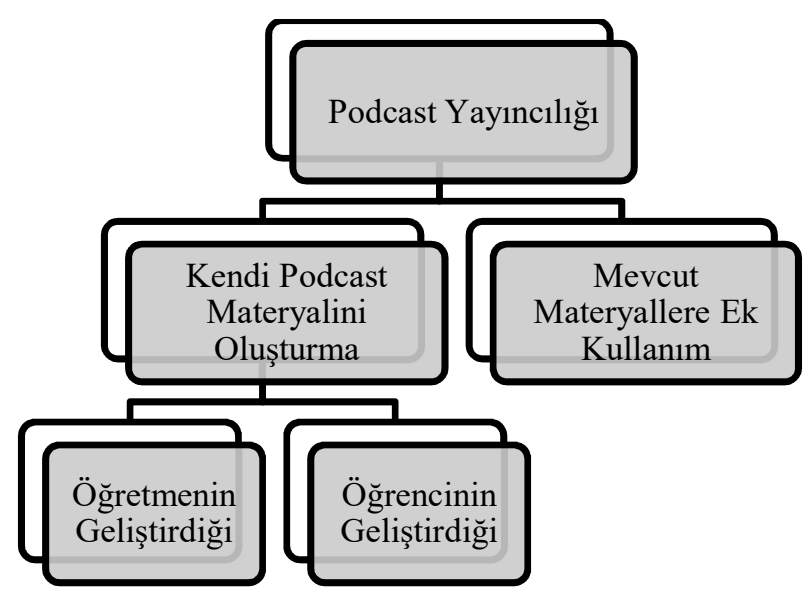

Şekil 2. Dil öğretiminde podcastin kullanım seçeneklerine ilişkin sınıflama

Podcastler, dil öğrenenlere gerçek dil ve gerçek materyal sunar, yapılandırıcı yaklaşımı destekler nitelik gösterir (Yılmaz ve Babacan, 2015: 1157). Nitekim Abdous vd. (2012), araştırmasında podcast kullanımının yabancı dil sınıflarında başarıya etkisini ve öğrenme sürecinde nasıl yararlanıldığını inceleyerek podcastin çoğunlukla alternatif ders materyali olarak kullanıldığını ve yabancı dil derslerinde başarıyı artırarak etkili olduğunu fark etmiştir. Literatürde, podcast ile dil öğretiminin ilişkilendirildiği, podcast kullanımının temel dil becerilerini desteklediği çalışmalara rastlanmıştır.

Podcastin dinleme öncesi hazırlıkta beyin fırtınası yapma, dinlediğini anlama, dinlediğini sorgulama, dinlediğine ilişkin sorulara cevap verme gibi dinleme/izleme çalışmalarında kullanılabileceği söylenebilir. Nitekim Bakla (2018), e-dinleti deneyiminin öğrencilerin konuşma ve dinleme becerileri üzerinde destekleyici olduğunu; Berk (2019), edinletilerin öğrencilerin dinlediğini anlama becerilerinin gelişiminde kullanılabileceğini; Harahap (2020), podcastin dinleme becerisini geliştiren bir araç olarak görüldüğünü, öğrencilerin ve öğretmenlerin bilgilerini zenginleştiren, eğitim için konu ve etkinlik alanı sağladığını ortaya koymuştur. Podcaste yönelik çalışmaların bir kısmı konuşma becerisiyle ilgilidir. Araştırmaları neticesinde Lord (2008), Ducate ve Lomicka (2008), podcast aracılığıyla öğrencilerin telaffuz becerilerini geliştirdikleri ve akıcı konuşma ürettiği; Hamzaoğlu (2015), e-dinletilerin öğrencilerin sözlü performansını geliştirdiği ve bunun sonucunda kelime hazinelerini zenginleştirdiği sonucuna ulaşmıştır.

Podcastler; bağlı olduğu uygulamada sağlık, tarih, eğitim, hikâye, politika, toplum ve kültür gibi konuları içeren kanallara sahiptir. Teknik özellikleri bakımından okumayla ilişkilendirilemeyeceği düşünülse de podcast yayınında bir eserden söz edilmesi, sesli kitap çalışmalarının yapılması veya kitap üzerine tartışmaların yürütülmesi bireylerin okumaya güdülenmesine, okunan esere ilgi duymasına yardımcı olabilir. Öyle ki Azis ve Puspitasari (2019), çalışmasında kapsamlı okuma çalışmaları yapılmış ve okunan kitapların incelendiği podcastler oluşturulmuştur. Çalışma sonuçları kitap inceleme podcastlerinin öğrencilerin okumaya ilgisini artırdığını ve okuma üzerinde olumlu etkisi olduğunu ortaya çıkarmıştır. Podcastler, bireylere dinlediği öyküyü devam ettirme, dinlerken not alma, dinlediğinin özetini oluşturma, dinlenileni yazma veya dikte etme gibi çeşitli etkinliklerle yazma çalışmalarını 
sergileyebilecekleri ortam sunabilir. Nitekim Bamanger ve Alhassan (2015), podcast dersleri vermenin geleneksel derslere ek olarak yazılarını geliştirme ve tutumlarındaki değişikliği incelediği bir çalışma yapmıştır. Çalışma sonucunda, öğrencilerin podcaste yönelik olumlu tutumda bulundukları, yazım ve noktalama hatalarını önemli ölçüde azalttıkları tespit edilmiştir.

İlgili çalışmalar, podcastin dil öğretiminde önemli bir yere sahip olduğunu yansıtmaktadır. Sonuç olarak öğrenci yaş, seviye ve ilgileri dikkate alınarak hazırlanan ya da kullanılan podcastlerin bütünleyici çalışmalar yapmaya imkân tanıyacağı ve Türkçe öğretim sürecini zenginleştireceği söylenebilir. Bu yaklaşımdan hareketle Türkçe derslerinde podcastin kullanılabilirliğine ilişkin örnek uygulamalar tasarlanmıştır. Örnek uygulamalar, 5. sınıf düzeyine yönelik hazırlanmış; temel dil becerilerinden dinleme, konuşma ve yazma ile sınırlandırılmıştır.

\section{Örnek Uvgulama 1}

Ders: Türkçe

Sinıf: 5. Sinif

Tema: Doğa ve Evren

Kaynak: Spotify (Müzik/Podcast Uygulaması)

Programın/Kanalın Adı: Serçeotu

Eserin Adı: Karadeniz'deki Yunus

Eserin Yazarı: Behiç Ak

Eserin Türü: Masal

Bağlantı Adresi:

https://open.spotify.com/episode/48YFH2mf462a8ZupfrXPM9?si=QSasHjhhRPyHvmdKRK AX2Q

Beceri Alanı: Dinleme

\section{Kazanımlar}

T.5.1.1. Dinlediklerinde/izlediklerinde geçen olayların gelişimi ve sonucu hakkında tahminde bulunur.

T.5.1.4. Dinlediklerinin/izlediklerinin ana fikrini/ana duygusunu tespit eder.

T.5.1.6. Dinledikleri/izlediklerine yönelik sorulara cevap verir.

T.5.1.11. Dinledikleriyle/izledikleriyle ilgili görüşlerini bildirir. 


\section{Dinleme Öncesi}

Öğretmen, Spotify uygulamasından Serçeotu kanalına ait "Karadeniz'deki Yunus" isimli masal türünde podcasti öğrencilere sunmadan önce dinleme öncesi hazırlık aşamasına uygun iki soru yöneltir:

1. "Doğa” kelimesinin sizde neler çă̆rıştırmaktadır? Öğretmeninizin yardımıyla bir zihin haritası oluşturunuz.

2. “Biz doğayı korudukça doğa da bizi korur.” sözüyle anlatılmak istenen nedir? Açıklayınız.

\section{Dinleme Sirası}

Öğretmen, Spotify uygulaması aracılığıyla Serçeotu kanalında bulunan "Karadeniz'deki Yunus" isimli masal türünde podcasti öğrencilere sunar. Öğretmen, öğrencilerin dinlediklerinde geçen olayın gelişimine ilişkin tahminde bulunmaları için masalı 2 dakika 31. saniyede durdurarak "Sizce denizde meydana gelen korkunç olay nedir?" sorusunu; olayın sonucuna ilişkin tahminde bulunmaları için masalı 7 dakika 48. saniyede durdurarak "Sizce bu masal nasıl sona ermiş olabilir?" sorusunu yöneltir.

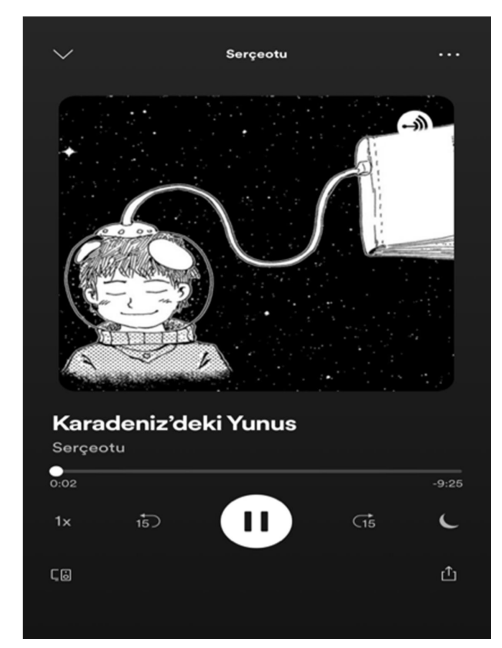

Görsel 4. Serçeotu kanalına ait “Karadeniz'deki Yunus” isimli podcast

\section{Dinleme Sonrası}

Öğretmen, "Karadeniz'deki Yunus" isimli masal türünde podcast için hazırladığ 4 soruyu öğrencilere yöneltir ve gelen cevaplar üzerine geri bildirimde bulunur. Böylece dinleme etkinliğinin ölçme değerlendirme aşaması tamamlanır.

1. Dinlediğiniz masalda geçen gerçek dişı durumlar nelerdir?

2. Balıkçılara göre, balıklar hangi sebeplerle yok olmaktadır?

3. "Karadeniz'deki Yunus" masalında verilmek istenen mesaj nedir?

4. Balıkçıların bir kısmının balıkçılıktan vazgeçmesi soruna çözüm olabilir mi? Siz olsaydınız nasıl bir çözüm üretirdiniz? 


\section{$\underline{\text { Önek Uygulama } 2}$}

Ders: Türkçe

Sinif: 5. Sinif

Tema: Okuma Kültürü

Kaynak: Spotify (Müzik/Podcast Uygulaması)

Programın/Kanalın Adı: Serçeotu

Eserin Adı: Kırık Şemsiye

Eserin Yazarı: Sevim Ak

Eserin Türü: Hikâye

Bağlantı Adresi:

https://open.spotify.com/episode/7bS00NrJws0FlftqIJ0iqn?si=I7GI1KiDS3q9ChBQRQ3h9A

Beceri Alanı: Yazma

\section{Kazanımlar}

T.5.4.4. Yazma stratejilerini uygular.

Güdümlü, metin tamamlama, bir metni kendi kelimeleri ile yeniden oluşturma, boşluk doldurma, grup olarak yazma gibi yöntem ve tekniklerin kullanılması sağlanır.

T.5.4.5. Büyük harfleri ve noktalama işaretlerini uygun yerlerde kullanır.

T.5.4.9. Yazdıklarını düzenler.

T.5.4.10. Yazdıklarını paylaşır.

\section{Yazma Öncesi}

Öğretmen, Spotify uygulamasından Serçeotu kanalına ait "Kırık Şemsiye" isimli hikâye türünde podcasti öğrencilere sunar. Öğretmen, hikâyeyi 3 dakika 44. saniyede durdurur ve öğrencilerden dinledikleri metni tamamlamalarını ister. 


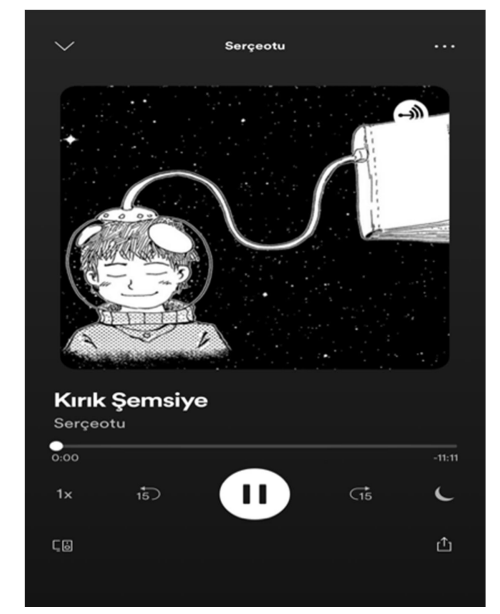

Görsel 5. Serçeotu kanalına ait "Kırık Şemsiye” isimli podcast

\section{Yazma Sonrası}

Öğretmen, öğrencilerin yazılarını tamamlamalarının ardından gözden geçirmelerine ve düzeltmelerine firsat tanır. $\mathrm{Bu}$ süreçte onlara rehberlik eder. Düzeltmeyi tamamlayan öğrenciler, metinlerini sınıfta paylaşırlar. Metinler, dereceli puanlama anahtarı yardımıyla değerlendirilir ve öğrenciye dönüt verilir.

\section{Örnek Uvgulama 3}

Ders: Türkçe

Sinıf: 5. Sinif

Tema: Milli Kültürümüz

Dijital İçerik Oluşturma ve Yayınlama Ortamı: Anchor ve Spotify

Beceri Alanı: Konuşma

\section{Kazanımlar}

\section{T.5.2.1. Hazırlıklı konuşma yapar.}

T.5.4.5. Konuşmalarında uygun geçiş ve bağlantı ifadelerini kullanır.

\section{Konuşma Öncesi}

Konuşma öncesi hazırlık bölümü, üç aşamalı olarak tasarlanır. İlk aşamada öğretmen, "Milli Kültürümüz" teması bağlamında öğrenciden geleneksel Türk sanatlarına dair bir araştırma yapmasını ister. İkinci aşamada öğrenci, araştırma sonucu edindiği bilgileri sınıfta paylaşır. Üçüncü aşamada öğretmen, öğrenciden geleneksel Türk sanatlarından birini seçmesini ve hakkında araştırma yapmasını ister. Araştırmasını derinleştiren öğrenci, seçtiği geleneksel Türk sanatı hakkında bilgi sahibi olur ve konuşmaya hazırlık bölümünü tamamlar. 


\section{Konuşma Sırası}

Öğrenci, hazırlık yaptığ 1 konuşma için Anchor isimli uygulama aracılığıyla "Record (Kayıt)" bölümünde kayıt oluşturur; "Save (Kaydet)" bölümünde oluşturulan kaydı kaydeder; “...” bölümünde uygulama imkânları ölçüsünde düzenleme (kaydı kesme, kaydın arka planına müzik ekleme vb.) yapar.

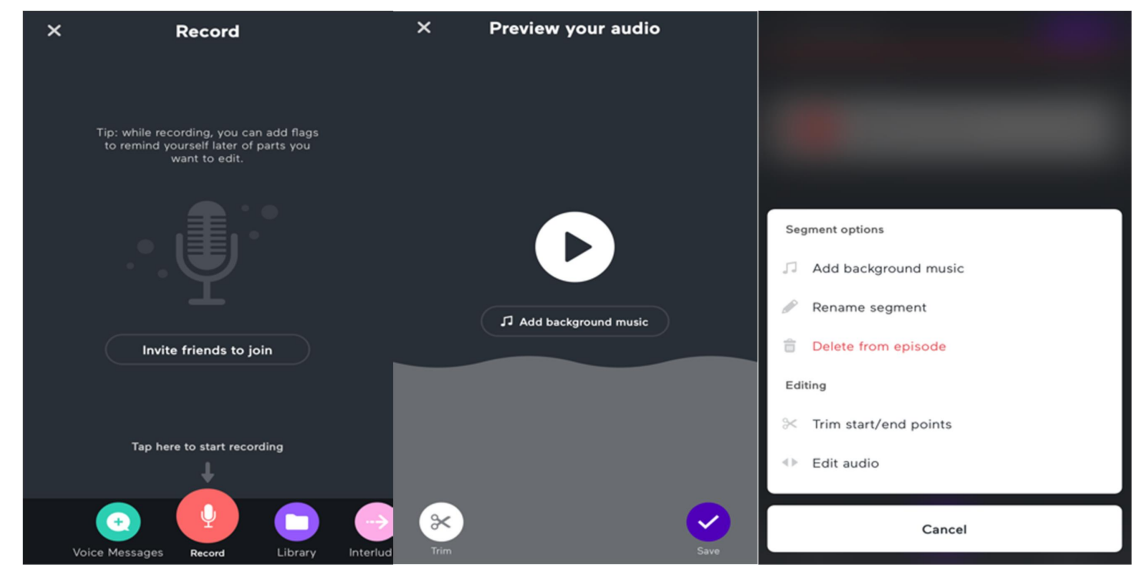

Görsel 6. Anchor isimli uygulamada podcast kaydı ve düzenlenmesi

\section{Konuşma Sonrası}

Öğrenci, Anchor'da oluşturduğu podcasti uygulamanın arayüzünde yer alan "Publish (Yayınla)" bölümü vasıtasıyla Spotify'da yayınlar. Öğrenci, Spotify’ın farklı sosyal platformlarda paylaşma imkânı sayesinde yakın çevresi, öğretmeni ve arkadaşlarıyla podcastini paylaşır. Öğrencinin yayınladı̆̆ı podcasti değerlendirmek isteyen öğretmen, dereceli puanlama anahtarından destek alır. Böylece ölçme ve değerlendirme aşamasının tamamlanmasıyla konuşma etkinliği son bulur.

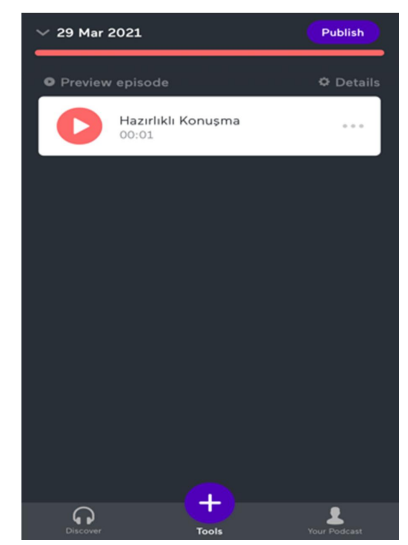

Görsel 7. Anchor isimli uygulamada podcastin paylaşımı

\section{TARTIŞMA VE SONUÇ}

2000'li yıllardan itibaren teknolojinin gelişmesi, internetin her hanede yer bulması ve mobil cihazların yaygınlaşmasıyla bilgi durdurulamayacak hızla akmaya başlamıştır. $\mathrm{Bu}$ 
y1llardan itibaren değişim, her alanda kendini göstermiştir. Eğitim, değişen ve dönüşen alanlardan biridir. Özellikle teknolojinin tanıştırdığı Web 2.0, eğitim üzerinde önemli bir yere sahiptir. Podcast, Web 2.0 araçlarından biridir. Podcastler, ses temelli olması ve alternatiflerinin bulunması (ses, video ve Web destekli) yönüyle ilgi çekicidir. Araştırmacılar, podcast teknolojisinin öğretmenlerin öğrencilerine etkili öğretim vermeleri ve öğrenme sürecini iyileştirmeleri için önemli bir yöntem olduğuna inanmaktadır (Beheler, 2007; Copley, 2007; Lord, 2008; akt. Bamanger, Alhassan, 2015: 65).

Podcast teknolojisine ilişkin yapılan literatür taramasında kayda değer sonuçlara ulaşılmıştır. Podcastler, yapılandırmacı yaklaşımın temeline uygun görülmekte (RosellAguilar, 2007), öğrenmeye katkı sunacak pedagojik bir araç olarak değerlendirilmektedir (Lane, 2006). Büyük bir dinleyici/izleyici kitlesine sahip olan podcastlerin ana dili olarak Türkçe öğretiminde kullanılabileği düşüncesi, bu çalışmanın temelini oluşturmaktadır. Nitekim incelenen çalışmalarda, podcastlerin dil eğitimi ile ilişkilendirildiği ancak bu çalışmaların büyük bir kısmını yabancı dil eğitiminin oluşturduğu fark edilmiştir. Podcastin yabancı dil eğitiminde kullanıldığını gösteren çalışmaların içinde sınırlı sayıda yabancı dil olarak Türkçe öğretimi yer alırken (Yılmaz ve Babacan, 2015; Coşkun ve Demirkan, 2016; Berk, 2019) ana dili olarak Türkçe öğretimine örnek verilebilecek bir çalışma bulunmamıştır.

Çalışmaların daha ziyade dinleme ve konuşma becerileri üzerine yapılandırıldığı, podcastlerin dinleme ve konuşma becerisini geliştirdiği yönünde sonuçlara ulaşılmıştır. Podcastlerin dinlediğini/izlediğini anlama, yorumlama, dinlenen/izlenen metinleri mukayese etme bakımından dinleme becerisini (Bakla, 2018; Berk, 2019; Alfian, Lio ve Marafat, 2019; Harahap, 2020); sözlü performansı geliştirme, telaffuzu iyileştirme, akıcı ve duru bakımından konuşma becerisini (Lord, 2008; Ducate ve Lomicka, 2008; Hamzaoğlu, 2015; Phillips, 2017; Koçak, 2017; Bakla, 2018) beslediği tespit edilmiştir. Podcast teknolojisinin teknik nitelikleri bakımından okuma becerisini doğrudan destekleyen bir araç olduğu söylenemese bile podcast yayınında bir eserden söz etmek, eserin tür özellikleri hakkında açılama yapmak, eserin içeriğine ilişkin tartışma gerçekleştirmek dinleyici ya da izleyicinin dolaylı da olsa kitaba karşı ilgi ve merak duymasını sağlayabilir. Azis ve Puspitasari (2019) yaptığı araştırmada, kitap okuma podcastlerinin öğrencilerin okuma ilgisini artırdığ 1 sonucuna ulaşmıştır. Aynı şekilde yazma becerisine de doğrudan katkı sunamayacağı düşünülen podcastler, dinlenen/izlenen metnin devamını getirme, dikte çalışması yapma gibi etkinliklerle yazma kurallarınıniçselleştirilmesini, daha az hata yapılmasını sağlayabilir. Bamanger ve Alhassan'ın (2015) araştırması, ileri sürülen bu ifadeyle kısmen örtüşmektedir. Nitekim çalışmanın sonuçları, podcast derslerinin geleneksel şekilde yürütülen derslere kıyasla çalışmaya katılanların yazım ve noktama hatalarını belirgin şekilde azalttığını ortaya koymuştur.

Tam tersi sonuçlar, 2009-2012 yılllarına işaret etmektedir. Yapılan çalışmaların sonuçları, teknoloji kullanımının kullanıcı beklentileriyle alakalıdır. Nitekim bu yıllarda podcast yayıncılığının pek tercih edilmediği, öğrencilerin daha ziyade sosyal medya platformlarını kullandıkları tespit edilmiştir (Atal, 2010; Atal ve Usluel, 2011; Altıntaş, 2012). Diğer araştırmalardan farklı olarak yalnızca bir araştırmada öğrencilerden toplanan veriler, podcastin kullanışsız olduğuna işaret etmiştir (Mckinney, Dyck ve Luber, 2009). 
Genel olarak podcast yayıncılığının dil eğitiminde kullanımı, araştırma sonuçlarına olumlu yansımıştır. Bu durum, Türkçe öğretiminde podcastten yararlanılabileceği kanısını güçlendirmektedir.

\section{4. ÖNERILER}

Yapılan çalışma neticesinde aşağıda yer alan öneriler geliştirilmiştir:

- Türkçe öğretmenleri; temaya, öğrenci seviye ve beklentilerine uygun podcastler hazırlayarak derslerinde kullanabilirler. Podcastler, dinleme/izleme sirasinda kullanılabildiği gibi dinleme/izleme veya okuma öncesi hazırlık amaçlı da tercih edilebilir. Özellikle podcast aracılığıyla beyin fırtınası yapılarak ön bilgiler öğrenme ortamına getirilebilir.

- Podcastler, okumayı teşvik edecek veya yolun okumaya çıkacağı içeriklerle yapılandırılabilir. Özellikle öğrencilerden oluşan grubun bir kitap üzerine tartıştığ podcasti yayınlaması, dinleyicilerin/izleyicilerin eser hakkında bilgi edinmesine ve okumaya güdülenmesine katkı sunabilir.

- Temeli metne dayanan podcast; deyim, atasözü, vecizelerin bağlamdan hareketle öğrenilmesi için bir firsat olarak görülmelidir. Dinlenilen/izlenilen podcastten yola çıkarak söz varlığını geliştirme maksatlı çalışmalar tasarlanabilir.

- Öğrencilerin podcast yayını yapmasına firsat tanınarak sözlü performansları geliştirilebilir. Buna ek olarak dinlenilen bir podcast üzerinde dikte etme, özet çıkarma, not alma gibi yazma etkinliklerinde bulunularak bütünleyici çalışmalardan yararlanılabilir.

- Öğrencilerin proje görevlerini hazırlamaları için yönergeler yazılı yerine podcast ile verilebilir. Bunun yanı sıra öğrenciler, proje görevlerini podcast aracılığıyla hazırlayabilirler. Örneğin proje sürecini ve tecrübelerini podcast aracılığıyla paylaşabilir, akranlarına farklı metin türlerini seslendirebilir, içeriğe görseller ekleyebilirler.

- EBA üzerinden temel dil becerilerini destekleyen podcast yayınları yapılabilir. Sosyal medya, dinleyicilerin/izleyicilerin yayınları düzenli takip etmeleri için aracı k1lınabilir.

- İkinci/yabancı dil olarak Türkçenin öğretiminde, öğrenenlerin hedef dile ait fonetik özellikleri fark etmeleri ve içselleştirmeleri için podcastler kullanılabilir.

\section{KAYNAKLAR}

Abdous, M., Facer, B. R. \& Yen, C. J. (2012). Academic effectiveness of podcasting: a comparative study of integrated versus supplemental use of podcasting in second language classes. Computer and Education, 58(1), 43-52. Doi: 10.1016/j.compedu.2011.08.021

Alfian, A., Lio, A. \& Marafat, L.O.S. (2019). The use of audio podcast for teaching listening comprehension. Journal of Language Education and Educational Technology, 4(1). 
Altıntaş, A. (2012). İlköğretim Öğrencilerinin Web 2.0 Kullanım Amaçları ve Ĕ̈ilimlerinin Belirlenmesi. (Yayımlanmamış yüksek lisans tezi). Hacettepe Üniversitesi Fen Bilimleri Enstitüsü, Ankara.

Atal, D. \& Usluel, Y. K. (2011). İlköğretim öğrencilerinin okul içinde ve dişında teknoloji kullanımları. Hacettepe Üniversitesi Eğitim Fakültesi Dergisi, 41, 24-35.

Atal, D. (2010). Informal öğrenme bağlamında öğrencilerin teknoloji kullanım durumları, beklentileri ve Web uygulamaları konusundaki görüşleri. (Yayımlanmamış yüksek lisans tezi). Hacettepe Üniversitesi Fen Bilimleri Enstitüsü, Ankara.

Ayvaz Reis, Z., Kartal E., Çelik, S. \& Özcan, P. (2009, Mayıs). Bir harmanlanmış öğrenme yöntemi eğitim aracı: podcast. III. İstanbul Bilişim Kongresi içinde (s.25-33), İstanbul.

Azis, A. R. \& Puspitasari, E. (2019). Book review podcasting in the implementation of extensive reading: exploring the students' benefits. Journal of Foreign Language Teaching \& Learning, 4(1), 28-42. Doi: 10.18196/ftl.4136

Bakla, A. (2018). Can podcast provide meaningful input in a listening and pronunciation class?. Kuramsal Eğitimbilim Dergisi, 11(4), 772-788. Doi: 10.30831/akukeg.382174

Bamanger, E. M. \& Alhassan, R. A. (2015). Exploring podcasting in English as a foreign language learners' writing performance. Journal of Education and Practice, 6(11), 6375.

Berk, R. R. (2019). Yabancı dil olarak Türkçe öğretiminde elektronik dinletilerin dinlediğini anlama başarısı ve dinleme kaygısına etkisi. (Yayımlanmamış doktora tezi). Gazi Üniversitesi Eğitim Bilimleri Enstitüsü, Ankara.

Boz, M. S. \& Çoban, Ö. (2015). Yabancı dil eğitiminde teknoloji kullanımı. Yenilik ve Eğitim Teknolojileri Genel Müdürlüğü, Ankara.

Cebeci, Z. \& Tekdal, M. (2006). Using podcasts as audio learning objects. Interdisciplinary Journal of Knowledge and Learning Objects, 2, 47-57. Doi: https://doi.org/10.28945/400

Coşkun, O. \& Demirkan, M. (2016, Nisan). Türkçenin yabancı dil olarak öğretiminde dinleme becerisini geliştirmede Web radyo ve podcast uygulamaları. Turkophone, 3(1), 35-56.

Çakır, H. \& Arslan, İ. (2011, Eylül). Mobil telefonlarına yönelik ders içerik paketinin geliştirilmesi ve tasarımı. $5^{\text {th }}$ International Computer \&Instructional Technologies Symposium. Firat Üniversitesi, Elazı ̆.

Çelik, B. (2014). Pre-service teachers' opinions, self-efficacy beliefs and state anxiety in relation to educational podcasting. (Yayımlanmamış yüksek lisans tezi). Ortadoğu Teknik Üniversitesi Fen Bilimleri Enstitüsü, Ankara.

Ducate, L. \& Lomicka, L. (2009). Podcasting: an effective tool for honing language students' pronunciation?. Language Learning \& Technology, 13(3), 66-86.

Edirisingha, P., Rizzi, C. \& Rothwell, L. (2007). Podcasting to provide peaching and learning support for an undergraduate module on English language and communication. Turkish Online Journal of Distance Education, 8(3), 87-107.

Göçer, A. \& Moğul, S. (2011). Türkçenin yabancı dil olarak öğretimi ile ilgili çalışmalara genel bir bakış. Turkish Studies, 6(3), 797-810.

Güler, S. (2014). Podcasting in pre-service language teacher education: a constructivist perspective. (Yayımlanmamış yüksek lisans tezi). Çukurova Üniversitesi Sosyal Bilimler Enstitüsü, Ankara. 
Gülseçen, S., Gürsul, F., Bayrakdar, B. \& Çilengir, S., Canım, S. (2010, Şubat). Yeni nesil mobil öğrenme aracı: podcast. XII. Akademik Bilişim Konferansı Bildirileri. Muğla Üniversitesi, Muğla.

Hamzaoğlu, H. (2015). Artzamanlı CMC'nin konuşma yeterliliği ve kaygısı üzerine etkisi: podcastler. (Yayımlanmamış yüksek lisans tezi). Yeditepe Üniversitesi Eğitim Bilimleri Enstitüsü, İstanbul.

Harahap, S. (2020). Podcast impacts on students listening skill: a case study based on students' perceptions. Jurnal Inovasi Penelitian, 1(4), 891-900. Doi: 10.47492/jip.v1i4.166

Hasan, Md. M. \& Hoon, T. B. (2013). Podcast applications in language learning: a review of recent Studies. English Language Teaching, 6(2), 128-135. Doi: 10.5539 / elt.v6n2p128

Işık, A. H., Özkaraca, O. \& Güler, İ. (2011, Şubat). Mobil öğrenme ve podcast. XIII. Akademik Bilişim Konferansı Bildirileri. İnönü Üniversitesi, Malatya.

İnce, H. G. (2015). EFL learners' perceptions of educational podcasting. (Yayımlanmamış yüksek lisans tezi). İhsan Doğramacı Bilkent Üniversitesi Eğitim Bilimleri Enstitüsü, Ankara.

İspir, B. (2013). Uzaktan eğitimde podcast kullanımı. T. V. Yüzer, G. Telli Yamamoto \& U. Demiray (Ed.). Türkiye'de e-öğrenme: gelişmeler ve uygulamalar IV içinde (s.29-47). Eskişehir: Anadolu Üniversitesi.

Jacob, S. M. \& Issac, B. (2008, March). The mobile devices and its mobile learning usage analysis. International Multi Conference of Engineers and Computer Scientists, Hong Kong.

Karaoğlan Yılmaz, F. G. (2014). E-öğrenme ortamlarında yansıtıcı düşünme etkinliklerinin ögrencilerin akademik başarısına, sosyal buradalı̆̆ına ve güdülenmesine etkisi. (Yayımlanmamış doktora tezi). Ankara Üniversitesi Eğitim Bilimleri Enstitüsü, Ankara.

Kay, R. H. (2012). Exploring the use of video podcasts in education: a comprehensive review of the literature. Computers in Human Behavior, 28(3), 820-831. Doi: 10.1016/j.chb.2012.01.011

Koçak, A. (2017). Developing speaking skills via creating and using learner podcasts in English language classes. (Yayımlanmamış doktora tezi). Hacettepe Üniversitesi Eğitim Bilimleri Enstitüsü, Ankara.

Lane, C. (2006). UW podcasting: evaluation of year one. Report by Office Learning Technologies, University of Washington.

Lord, G. (2008). Podcasting communities and second language pronunciation. Foreign Language Annals, 41(2), 364-379. Doi: 10.1111/ j.1944-9720.2008.tb03297.x

McKinney, D., Dyck, J. L. \& Luber, E. S. (2009). iTunes university and the classroom: can podcasts replace professors?. Computers and Education, 52(3), 617-623. Doi: 10.1016/j.compedu.2008.11.004

Ormond, Pat R. (2008). Podcasting enhaces learning. Journal of Computing Sciences in Colleges, 24(1), 232-238.

Öz, H. (2014, Kasım). Mobil öğrenme, mobil dil öğrenme. II. Ulusal Yabancı Dil Çalıştayı Bildirileri. Ondokuz May1s Üniversitesi, Samsun. Doi: 10.13140/2.1.4122.3366 
Phillips, B. (2017). Student-produced podcasts in language learning-exploring student perceptions of podcast activities. IAFOR Journal of Education, 5(3), 157-171.

Rosell-Aguilar, F. (2007). Top of the pods-in search of a podcasting "podagogy" for language Learning. Computer Assisted Language Learning, 20(5), 471-492. Doi: 10.1080 / 09588220701746047

Şengül, M. (2014). Effects of podcasts on $9^{\text {th }}$ grade students' attitudes towards foreign language learning and their listening skills in Hatay. (Yayımlanmamıs yüksek lisans tezi). Mustafa Kemal Üniversitesi Sosyal Bilimler Enstitüsü, Hatay.

Tarımer, İ. \& Okumuş, T. (2010, Şubat). Mobil iletişim cihazlarının eğitim aracı olarak kullanılması. XII. Akademik Bilişim Konferansı Bildirileri. Muğla Üniversitesi, Muğla.

Usluel, Y. K. \& Mazman, S. G. (2009). Adoption of Web 2.0 tools in distance education. International Journal of Human Sciences, 6(2), 89-98. Doi: 10.1016/j.sbspro.2009.01.146

Vogt, M., Scaffner, B., Ribar, A. \& Chavez, R. (2010). The impact of podcasting on the learning and satisfaction of undergraduate nursing students. Nursing in Practice, 10(1), 38-42. Doi: 10.1016 / j.nepr.2009.03.006

Yeşiltaş, E. (2020). Sosyal bilimlerde uzaktan eğitimin Web 2.0 teknolojileri açısından Analizi: dijital içerik üretme ve yayınlama araçları. Erol Koçoğlu (Ed.) Sosyal Bilimlerde Uzaktan Ĕgitime Bakış içinde (s.220-236). Ankara: Pegem Akademi.

Yılmaz, F. \& Babacan, G. (2015). Yabancı dil olarak Türkçe öğretiminde podcast kullanımı. International Periodical for the Languages, Literature and History of Turkish or Turkic, 10(3), 1153-1170.

Atıf İçin/For Citation: Kurt, A. ve Göçer, A. (2021). Mobil öğrenme aracı olarak podcastin Türkçe öğretiminde kullanılabilirliği üzerine: kuramsal bir çalışma. Uluslararası Eğitim Bilim ve Teknoloji Dergisi,7(2), 77-97. 